\title{
Revising the Principle of Alternate Possibilities Max Siegel
}

\begin{abstract}
This paper examines the position in moral philosophy that Harry Frankfurt calls the Principle of Alternate Possibilities (PAP). The paper first describes the principle as articulated by A.J. Ayer. Subsequently, the paper examines Frankfurt's critique and proposed revision of the principle and argues that Frankfurt's proposal relies on an excessively simplistic account of practical reasoning, which fails to account for the possibility of moral dilemmas. In response, the paper offers a further revision of PAP, which accounts for Frankfurt's critique, moral dilemmas, and the challenge of causal determinism.
\end{abstract}

A highly contested position within moral philosophy and the free will debate is the Principle of Alternate Possibilities (PAP), which holds that "a person is morally responsible for what he has done only if he could have done otherwise." ${ }^{11}$ At first glance, this principle seems intuitive-it accords with our view that coercion exempts one from moral responsibility. However, PAP is actually quite problematic, as it seems that individuals can be morally responsible for certain actions, even when they could not have done otherwise. In this paper, I will discuss the problems of PAP, explain one prominent proposed revision to the principle, and also offer an alternative position that better accords with our considered moral judgments.

This paper proceeds in five sections. I begin by discussing A.J. Ayer's defense of PAP and articulating the apparent merits of his position. Second, I explain Harry Frankfurt's well-known challenge to PAP, which I illustrate through counterexamples. Third, I explain Frankfurt's proposed revision to PAP. Fourth, I criticize Frankfurt's proposed revision, showing that it presents an excessively simplistic picture of practical reason and thus fails to capture our intuitions about responsibility in moral dilemmas. I suggest an alternate revision that might be more successful. Finally, I address several possible objections to my view.

In his "Freedom and Necessity," A.J. Ayer attempts to save moral responsibility from the challenge of determinism by claiming that moral responsibility requires not freedom from causal determination but rather freedom from constraint. ${ }^{2}$ First, Ayer denies the relevance of causal determinism to moral responsibility. His argument is as follows: according to those who invoke causal determinism, we are not responsible for our actions if they were determined according to causal laws. At the same time, we are not responsible for our actions if they were not determined according to

\footnotetext{
${ }^{1}$ Harry Frankfurt, "Alternate Possibilities and Moral Responsibility," The Journal of Philosophy 66, no. 23 (1969): 829.

2 A.J. Ayer, "Freedom and Necessity," in Free Will, ed. Gary Watson (Oxford: Oxford University Press, 1982), 22.
} 
causal laws, as such actions must be the result of chance. As such, anyone who attempts to defend moral responsibility by denying the thesis of determinism will fail to defend moral responsibility. As an alternative, then, Ayer tries to tie moral responsibility to a different sort of freedom: freedom from constraint, which implies the existence of alternate possibilities. On this account, an agent $B$ acts freely when the following conditions are met: (1) if B had chosen to act otherwise, she would have done so, (2) B's action was voluntary insofar as her deliberation was efficacious and not constrained by a psychological abnormality (e.g., kleptomania), and (3) nobody compelled B (e.g., through coercion) to act as she $\mathrm{did}^{3}$

To this account, the hard determinist might object that condition (1) is insufficient because B is causally determined to choose as she does and thus never could choose to act otherwise. Putting aside this objection, as it does not address the legitimacy of PAP but rather the existence of alternate possibilities, we can see that Ayer's account is grounded in PAP. The ability to choose and do otherwise, the freedom of one's deliberation, and the absence of constraint all refer to B's freedom to choose to $\psi$ rather than to $\phi$, where $\psi$ represents any action aside from $\phi$. When B lacks the freedom to $\psi$, she is not responsible for $\phi$-ing. Condition (1) would be violated, as B could not $\psi$ even if she chose to. Condition (2) may be violated, if B cannot $\psi$ because of a psychological abnormality. Condition (3) may also be violated, if B's inability to $\psi$ is a result of another's coercion. We can thus see the appeal of PAP, insofar as conditions (1), (2), and (3) appear to conform to our intuitions regarding moral responsibility. A failure of any condition appears to exempt B from responsibility.

However, Harry Frankfurt poses a robust and effective challenge to PAP, which weakens Ayer's position. While Frankfurt presents several counterexamples, I will focus on the one that I find most effective. In this example, Black wants Jones to perform a particular action. He is willing to use force in order to ensure that Jones performs this action, but Black chooses not to get involved unless necessary. As it turns out, Jones wants to perform the action that Black desires. Without any knowledge of Black's presence, Jones performs this action. In this case, Jones could not have done otherwise. Black was ready to use coercion if Jones deviated from the desired course of action. However, Jones shared Black's desire that this action be performed and thus performed the action independently, without the influence of an external constraint. Here, Ayer's condition (1) is violated. If Jones had chosen to do otherwise, he would not have been able to do so, as Black would have forcefully intervened. We might say that condition (3) was also violated; Jones was subject to another's constraint and potential compulsion even though he did not act as to test the constraint. However, Jones is still morally responsible, even though he could not do otherwise. A constraint was in place, but Jones' action was fully "his own," so to speak. PAP is thus a flawed principle. Even when an agent cannot do otherwise, she can still be responsible for acting as she does.

${ }^{3}$ Ibid., 22. 
As PAP is very much embedded in our moral discourse, Frankfurt offers a revised version that aims to correct PAP's flaws. He suggests "a person is not morally responsible for what he has done if he did it only because he could not have done otherwise." ${ }^{\prime 4}$ His argument for this revision is twofold. First, the revision solves the problem of the original version of PAP by requiring that the lack of alternate possibilities actually affect a person's actions and not merely lurk as an unconsidered background condition. In the above example, Jones would be morally responsible because even though he could not have done otherwise, this fact was unknown to him and thus affected neither his practical reasoning nor the causation of his action. Second, the revision solves the problem presented by an alternate candidate revision-"a person is not morally responsible for what he has done if he did it because he could not have done otherwise," identical without the word "only"-by forcing us into a reasons-based reading of "because," rather than a merely causal reading. ${ }^{5}$ When one invokes the absence of alternate possibilities as an excuse, one typically means that one was forced to act against one's settled reasons. As Frankfurt puts it, one who invokes PAP typically means "when he did what he did it was not because that was what he really wanted to do."6 $\mathrm{B}$ is not exempt from responsibility if he wants to $\phi$ and is coerced into doing so on top of his preexisting desire. When we invoke PAP, it is because we believe that the absence of alternate possibilities was the operative factor leading to B's $\phi$-ing, and Frankfurt's principle appears to capture this intuition.

However, Frankfurt's position suffers from a critical flaw. As above, Frankfurtclaims "apersonis notmorallyresponsibleforwhathehasdoneifhedid it only because he could not have done otherwise" (emphasis added). ${ }^{7}$ However, this principle fails to account for the possibility of moral dilemmas: cases in which reasonable moral claims compete and cannot both be satisfied. Frankfurt mistakenly assumes that a person can have no reason for acting against her freely chosen course of action, but this view is incorrect. Consider the following case, a classic trolley problem. Martha must choose between pushing a fat man onto the railroad tracks to save five railroad workers from an oncoming train or letting the fat man live while the railroad workers die. ${ }^{8}$ Having studied some moral philosophy, she is familiar with both the Kantian position, which claims that the fat man is inviolable and that Martha ought not to push him, and the utilitarian position, which claims that Martha cannot prioritize any individual's happiness and ought to save the five railroad workers to maximize utility. Martha finds both positions compelling and believes that both provide normative reasons. Indeed, during her deliberation, she walks towards and away from the fat man several times, reversing her position, as she is actually motivated by both positions. The Kantian and utilitarian arguments both appear

\footnotetext{
${ }^{4}$ Frankfurt, 838 .

${ }^{5}$ Ibid.

${ }^{6}$ Ibid.

${ }^{7}$ Ibid.

${ }^{8}$ The "fat man" formulation of the trolley problem is due to Judith Jarvis Thomson, "Killing, Letting Die, and the Trolley Problem," The Monist 59 (1976): 204-17.
} 
to give her normative and motivating reasons. After lengthy deliberation, she decides not to push the fat man and walks away. As she is leaving, a gunman approaches her and orders her to push the fat man. Martha pushes the fat man because she cannot do otherwise. In this case, the effect of coercion exempts Martha from moral responsibility. Her action went against the balance of her reasons. However, it does not seem that she pushed the fat man only because she could not do otherwise. We saw above that she had normative reasons to follow the utilitarian route and that she was even motivated by these reasons. Normative reasons do not drop away when one chooses to act against them. One can maintain a reason to $\psi$ even after she has decided to $\phi$. Frankfurt's principle cannot exempt Martha from responsibility because she had two reasons for pushing the fat man: a considered moral judgment and a need to avoid death, which made her unable to do otherwise. Frankfurt's principle thus fails to capture cases of moral dilemmas.

As such, I propose yet another revision of PAP. In this version, we view PAP as a counterfactual, which draws somewhat closer to Ayer's position as I articulated it above. In essence, PAP should absolve one from moral responsibility when the fact that a person could not do otherwise tipped the balance of reasons in favor of an action that the person would not have performed absent the constraint. For example, like Martha, a person might have strong reasons to $\phi$ but stronger reasons not to $\phi$; she thus decides not to $\phi$. If coercion then tips the balance in favor of $\phi$-ing, she is not morally responsible, even though she had some reasons to $\phi$ that emerged from her previously free deliberation. The revised principle is thus as follows: a person is not morally responsible for what she has done when (1) she acted as she did because she could not have acted otherwise, (2) her action went against the balance of her normative reasons aside from the constraint that made her unable to act otherwise, and (3) her action was substantively different from what she would have done absent the constraint. The first condition accounts for Frankfurtstyle cases, the second ensures a reasons-based reading of "because" but without taking Frankfurt's simplistic view of practical reason, and the third accounts for true irrationality, weakness of the will, and other cases where people act against the available reasons. The second and third conditions together also account for those who wanted to $\phi$ and whose actions were subsequently overdetermined by coercion to $\phi$. This principle requires that one could not do otherwise, that this constraint was a factor in one's practical reasoning, and that this constraint was decisive against the balance of other available reasons. The constraint need not be the only reason in favor of $\phi-$ ing, but it must tip the balance in favor of $\phi$-ing. By revising the principle in this way, we maintain that one is not responsible for coerced acts, correct for the counterexamples presented by Frankfurt, avoid a purely causal reading of "because," and allow for the possibility of moral dilemmas.

Some might object to my position on the grounds that previously rejected reasons cannot retain any motivational force for an agent. In the trolley problem, Martha's having rejected utilitarian reasoning means that she could not have been motivated by such reasoning when she subsequently chose to push the fat man onto the tracks. However, we can modify this case to see that 
this objection is misguided. In a modified version of the case, Martha initially favors the utilitarian position over the Kantian position, but she is weak of will and thus fails to push the fat man onto the tracks. She turns to walk away and is confronted by the gunman, who orders her to push the fat man. In this case, Martha might feel a sense of relief; she might be grateful for the approach of the gunman, which enabled her to overcome her akrasia and act in accordance with her considered moral judgment. In this case, Martha acts for the dual reasons of coercion and her belief that she has a duty to maximize utility. If we ask her why she acted as she did, she would point to both of these reasons. Frankfurt's revised version of PAP would call Martha morally responsible for her actions in this case, since she acted as she did both because she could not do otherwise and because she wanted to comply with utilitarianism. However, Martha's action was not truly "her own." Absent coercion, she would not have acted as she did. As such, this revised case confirms that one can be motivated by previously rejected reasons, even if coercion is an important factor in one's practical reasoning, and suggests that we should favor my revision of PAP over Frankfurt's.

A further objection to my view might be that Ayer's position accounts for cases like Martha's and, on one reading, is also compatible with Frankfurt's critique. One might say that Ayer's first condition-that if B had chosen to act otherwise, she would have done so-is compatible with Frankfurt's principle if it is read as a sufficient rather than a necessary condition. We see from the Jones case that this condition can be violated, and one can still be morally responsible. However, if this condition is met, we rule out the possibility of exemption by lack of alternate possibilities. One who could act otherwise but does not do so is not even exempted by the original version of PAP. The second condition-that B's deliberation was effective-is unaffected by Frankfurt's principle. When we exempt someone psychologically abnormal from moral responsibility, we are not appealing to their inability to do otherwise but rather to the fact that their deliberation has been impaired all along. Even if psychologically impaired person B could have chosen to $\psi$ rather than to $\phi$, B would still not be responsible. The third condition-that B's action was not constrained or compelled by another person-aims at the same effect as Frankfurt's principle and requires only moderate revision. We saw above that in Jones' case, condition (3) was violated, but Jones was still responsible. However, if we revise condition (3) to state that the constraint or compulsion by another was the only reason that B chose to $\phi$, we end up with Frankfurt's result. If we instead say that the constraint or compulsion was an operative reason that $\mathrm{B}$ chose to $\phi$, some might say that we also account for the case of Martha.

Ayer's position, however, is subject to the challenge of causal determinism in a way that my position is not. As above, Ayer's first condition for moral responsibility is that if an agent had chosen to do otherwise, she would have done otherwise. However, if determinism is true, an agent will never be able to choose or do otherwise. This counterfactual, then, will be irrelevant, and Ayer's position will leave psychological abnormality and coercion as 
the only two conditions that could exempt one from moral responsibility. However, these are not the only two exempting conditions available to agents. Some agents act as they do and are exempt from moral responsibility because of physical disability or situational constraints, among many other factors. Revising Ayer's position to make it a suitable alternative to PAP would require developing a long list of exempting conditions and result in a clumsy, highly complicated principle. For theoretical simplicity and to avoid the challenge of causal determinism, we should opt for my position.

We have seen that the principle of alternate possibilities has great appeal but is deeply flawed. Though it requires some revision, PAP captures an important intuition about moral reasoning: namely, that constraint and compulsion can absolve one of moral responsibility, albeit only in specific circumstances. The lack of alternate possibilities is not sufficient to exempt one from moral responsibility, but when this constraint substantively impacts one's actions, a revised version of PAP may grant one exemption. When reformulated as I propose, PAP can effectively distinguish between cases of responsibility and cases where constraint voids responsibility. Though critical of both Ayer and Frankfurt, my position recognizes the merits of both and corrects for possibilities that they overlook..$^{9}$

\footnotetext{
${ }^{9}$ I owe many thanks to Professor Victoria McGeer for her guidance in the preparation of this paper and to anonymous referees for their helpful comments on an earlier draft.
} 
Copyright of Stance (1943-1880) is the property of Ball State Innovation Corporation and its content may not be copied or emailed to multiple sites or posted to a listserv without the copyright holder's express written permission. However, users may print, download, or email articles for individual use. 